\title{
Temporal and spatial change of exergy and ascendency in different benthic marine ecosystems
}

\author{
M. Fabiano ${ }^{\text {a }}$, P. Vassallo ${ }^{\text {a,*, L. Vezzulli }}{ }^{\text {a }}$, V.S. Salvo ${ }^{\text {a }}$, J.C. Marques ${ }^{b}$ \\ ${ }^{a}$ Dipartimento per lo studio del territorio e delle sue risorse, University of Genoa, Corso Europa 26, \\ 16132 Genova, Italy \\ ${ }^{\mathrm{b}}$ IMAR (Institute of Marine Research), Departement of Zoology, University of Coimbra, 3000 Coimbra, Portugal
}

Received 28 July 2003

\begin{abstract}
Holistic indicators such as exergy and ascendency have been widely employed to assess the health of ecosystems given by their structure, function and organization. In this study we calculate the exergy, specific exergy and ascendency for the microbenthic loop that represents a major sub-system within the marine food chain. The analysis of the microbenthic loop investigated in terms of organic matter, bacteria, microphytobenthos and meiofauna reflected changes occurring in the trophic state of benthic ecosystems and provided a tool for comparison between different environments. Temporal and spatial variability of the holistic indicators were evaluated using benthic measures collected at different times for different environments in the Mediterranean Sea. Exergy was strongly correlated with the organic contents of the sediments, and did not provide a useful description of the investigated system. In contrast, specific exergy resulted related to the microbenthic loop structure and complexity while Ascendency mostly reflected its activity and organization. Temporal analysis showed that in natural ecosystems specific exergy and ascendency showed convergence and follow similar seasonal trends. On the contrary in strongly eutrophicated systems an uncoupling between the two indicators occurred indicating a malfunctioning of the microbenthic loop that become strongly dissipative.

As a result specific exergy and ascendency calculated within the microbenthic loop appeared to be sensitive to changes in environmental conditions and trophic state and may be proposed as useful tools for the health assessment of marine benthic ecosystems.
\end{abstract}

(C) 2004 Elsevier Ltd. All rights reserved.

\footnotetext{
* Corresponding author. Tel.: +39-010-3538069; fax: +39-010-3538041.

E-mail address: vassallo@fisica.unige.it (P. Vassallo).
} 


\section{Introduction}

Many researchers have suggested operational definitions and indicators of ecosystems health [1-4]. Unfortunately, there are several methods of measuring or quantifying the particular symptoms of distress potentially resulting in an inordinate number of ecosystem health indicators [4]. Qualitative alterations in the ecosystems (biomass, species composition, activity) could be detected by exergy [5-9] and ascendency [10,11] that measure the ecosystem structure, its function and organization. Exergy and specific exergy are two thermodynamic indicators derived from ecosystem theory. The exergy index (Ex) was first applied to ecological study in the late 1970s [12]. Exergy considers, besides the free energy of biomass as fuel, the information embodied in the biomass structure. The thermodynamic definition of exergy is the amount of work the system can perform by being brought into equilibrium with its environment [6]. As ecological indicator, exergy was used to assess the health and ecological condition of aquatic ecosystems $[6,8,13]$.

Ascendency is a network oriented indicator and its ecological application was first proposed by Ulanowicz [11]. Ulanowicz [11] defines ascendency as an index that quantifies both the level of system activity and the degree of its organization whereby it processes material in autocatalytic fashion.

Several studies aimed at the comparison of different ecosystems using exergy and ascendency as ecological indicators of health [5,7,13-16]. However, in all these studies the ecosystem was mostly investigated in a broader sense (i.e. ecosystem as a whole) and to our knowledge no attempts have been made to focus attention on particular sub-systems whose structure and organization may be of particular interest for the definition of ecosystem health relative to a specific disturbance.

In this study, we focus on the trophic state of the benthic marine environment to provide a tool for the comparison and assessment of the benthic health of ecosystems. We investigate at a new approach to assessing the ecosystem health based on the use of the microbenthic loop for the calculation of exergy and ascendency.

The microbenthic loop is a major sub-system within the marine food chain and its role in affecting ecosystem function has raised increasing interest since it was first described in 1983 [17]. The microbenthic loop encompasses organic matter, bacteria, microphytobenthos, protozoa and meiofauna and the state of its structure and dynamics, have been recently proposed as sensitive indicators of the changes occurring in marine ecosystems [18,19]. In particular, organic matter and bacteria are considered as powerful tools for assessing the trophic state and quality of the benthic marine environment [20,21].

In order to investigate the trophodynamics of the benthic ecosystem we combine past observations and more recent data in an integrative manner, providing an interpretation of the biological responses within the microbenthic loop as a function of different ecological scenarios. To capture the state of the systems we make use of the mentioned holistic indicators. In particular we evaluate the spatial and temporal changes of exergy, specific exergy and ascendency within the microbenthic loop system in different benthic environments. 


\section{Methods}

The calculation of exergy, specific exergy and ascendency within the microbenthic loop was made by using data on organic matter, bacteria, microphytobenthos and meiofauna for 52 stations located in eight different environments (see Section 3 for details on the stations and the benthic environments employed in the study). Identification of meiofauna taxonomic groups reaches a taxon level resolution according to the weighting factors for the calculation of exergy [22]. Major meiofauna taxa employed in the calculation were nematodes, polychaetes, copepods and turbellarians. Nematodes were further identified in four nutritional groups following microscope examination of the feeding apparatus (selective deposit feeders, unselective deposit feeders, epigrowth feeders and omnivorous feeders).

Benthic measures and groups used for the calculation of exergy and ascendency within the microbenthic loop system are reported in Table 1. Units of measure for each group were standardized to ton $\mathrm{km}^{-2}=\mathrm{g} \mathrm{m}^{-2}$.

\subsection{Exergy}

The exergy index was calculated as the concentration of different groups $c_{i}$ multiplied by weighting factors $\beta_{i}$, based on exergy detritus equivalents according to Marques and Jørgensen [22] (Table 1). Exergy links the chemical energy of the various groups of the ecosystem to the information embodied in DNA as explained by the following equation:

$$
\mathrm{Ex}=\sum_{i} \beta_{i} * X_{i}
$$

where $\beta_{i}$ are the weighting factors and $X_{i}$ are the concentrations of each group in the system.

Unit exergy detritus equivalents are expressed in $\mathrm{g} \mathrm{m}^{-2}$ and can be converted to $\mathrm{kJ} \mathrm{m}^{-2}$ by a factor of 18.7 corresponding to the approximate average energy content of $1 \mathrm{~g}$ of detritus [7].

A variation in exergy values could be due to variations of biomass or to variations of the structural complexity of the biomass. This latter assess for the information embedded in the

Table 1

Values of the "qualities" of the biomass expressed by the weighing factors [22]. The weighing factors values are based on the number of information genes. The exergy content of organic matter in the various organisms is compared with the exergy contained in detritus

\begin{tabular}{ll}
\hline Organisms & Weighing factors $\beta$ \\
\hline Detritus & 1 \\
Bacteria & 3 \\
Algae & 3.9 \\
Annelid & 50 \\
Crustacean zooplancton & $30-46$ \\
Crustacean (decapods) & 230 \\
Fish & $287-344$ \\
Amphibians & 800 \\
Reptiles & 1000 \\
Birds & 1100 \\
\hline
\end{tabular}


DNA and could be called the specific exergy or exergy per unit of biomass. Specific exergy is given by:

$$
\mathrm{Ex}_{\mathrm{sp}}=\mathrm{Ex} / \text { Total biomass }
$$

\subsection{Ascendency}

Ulanowicz and Abarca-Arenas [23] assert that ascendency incorporates aspects of both a system's size and constitutive nature. $T$, the total system throughput, gauges the level of overall system activity; the index $I$ measures the organization by which exchanges among components are transacted. The ascendency (AS) is calculated as the product of $T$ and $I$. An increase of AS is linked to the growth and development of the system [11].

Computation of ascendency used the following equations:

$$
\begin{aligned}
& T=\mathrm{TST}=\sum_{i} T_{i} \\
& I=k \sum_{i=1}^{n} \sum_{j=1}^{n}\left(T_{i j} / T\right) \log \left(T_{i j} B^{2} / B_{i} B_{j} T\right)
\end{aligned}
$$

where $k$ is constant, $T_{i j}$ is the flux out of $i$-group and going in $j$-group, $T$ is the sum of all the fluxes in the system and $B_{i}$ is the biomass of $i$-group.

$$
\mathrm{AS}=T * I=\sum_{i=1}^{n} \sum_{j=1}^{n} T_{i j} \log \left(T_{i j} B^{2} / B_{i} B_{j} T\right)
$$

Ascendency was calculated using the software Ecopath with Ecosim [24].

\subsection{Basic modelling approach}

The models for each study area were created using Ecopath 5.0 software which for each group (array of species with similar ecological attitude) uses a set of linear equations in order to balance the flows (in and out) of each compartment [24].

For a basic parameterization the model's routine uses a system of linear equations, which can be expressed for an arbitrary time period by:

$$
B_{i} *\left(\frac{P}{B}\right)_{i} * \mathrm{EE}_{i}=C_{i}+\sum_{j=1}^{n}\left[B_{j} *\left(\frac{Q}{B}\right)_{j} * \mathrm{DC}_{i j}\right]
$$

Consequently the software needs five parameters for each group: biomass $(B)$, production/biomass ratio $(P / B)$, consumption/biomass ratio $(Q / B)$, ecotrophic efficiency (EE) and diet composition input $\left(\mathrm{DC}_{i j}\right)$. If one of these parameters is not available it could be calculated by four additional parameters: unassimilated/consumption (GS), net migration rate $(E)$, biomass accumulation (BA) and catch mortality $(Y)$.

In this study ecotrophic efficiency was always estimated considering $E$, BA and $Y$ null for each simulation. 


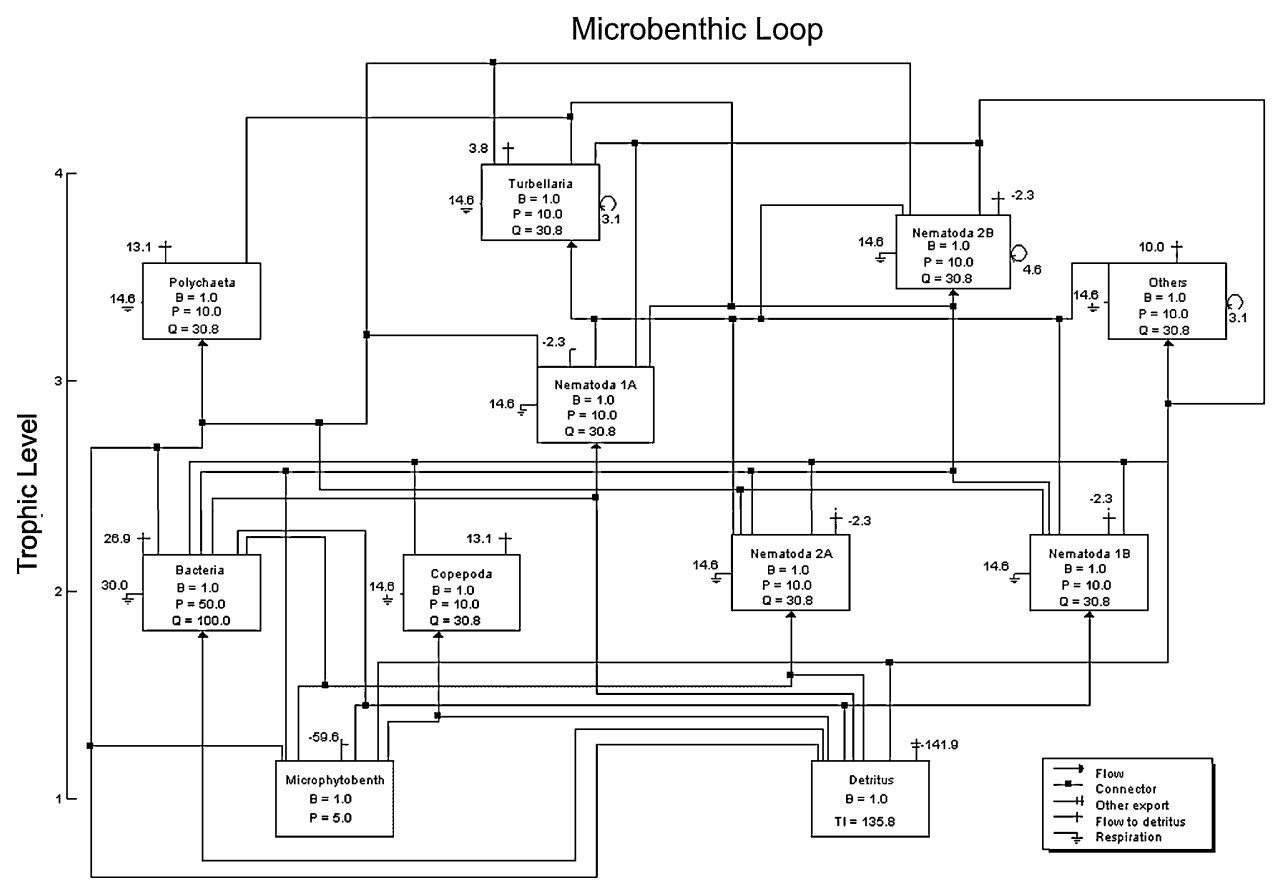

Fig. 1. Standard flow diagram for the microbenthic loop sub-system based on the starting diet matrix with all the biomass forced to 1 .

The model compartments consist of 11 different groups: one primary producer, nine consumers and one non-living group (detritus compartment).

The software routine gives an error message if the model output is not realistic. In particular it checks if the ecological efficiency is $<1.0$ for all compartments. If inconsistencies were detected, the diet matrix was slightly adjusted until the simulation procedure can perform. Fig. 1 shows a standard flow diagram that has been employed for the microbenthic loop sub-system based on the starting diet matrix with all the biomass forced to 1 .

\section{Marine benthic ecosystems}

Eight marine ecosystems were selected for the study of spatial and temporal changes of exergy and ascendency. In each system a minimum of 2 to a maximum of 13 stations were selected. For each station the same benthic measures were employed for the calculation of the ecological indicators (Table 2).

\subsection{Prelo Bay (Ligurian Sea)}

Prelo station is located in the Gulf of Tigullio in the Ligurian Sea (Fig. 2A). The bay is sheltered and is characterised by an extended seagrass bed of Posidonia oceanica located at $0.4-9 \mathrm{~m}$ 
Table 2

Benthic parameters and groups expressed as ton $\mathrm{km}^{-2}$ utilised for the calculation of exergy and ascendency within the microbenthic loop system

\begin{tabular}{lll}
\hline Benthic parameters & Groups & References \\
\hline Chlorophyll- $a$ & Microphytobenthos & Plante-Cuny [25] \\
Bacteria biomass & Bacteria & Meyer-Reil [26] \\
& Nematodes (selectives & Wieser [27]; Warwick and Price [28]; \\
deposit-feeders) & Romeyn and Bowman [29] \\
Nematodes (non selective & Wieser [27]; Warwick and Price [28]; \\
deposit-feeders) & Romeyn and Bowman [29] \\
Nematodes & Wieser [27]; Warwick and Price [28]; \\
(epigrowth-feeders) & Romeyn and Bowman [29] \\
Nematodes & Wieser [27]; Warwick and Price [28]; \\
(predators-feeders) & Romeyn and Bowman [29] \\
& Copepods & Wieser [30]; Warwick and Price [28] \\
& Polychaeta & Wieser [30]; Warwick and Price [28] \\
& Turbellaria & Wieser [30]; Warwick and Price [28] \\
Others & Wieser [30]; Warwick and Price [28] \\
Total organic matter & Detritus & Parker [31] \\
\hline
\end{tabular}

of depth [32]. Sampling was carried out at monthly interval from January 1991 to January 1992 in the middle of the bay. Sampling depth ranged from 8 to $10 \mathrm{~m}$.

\subsection{Zoagli Coast (Ligurian Sea)}

Zoagli station is located east of Prelo Bay in the Tigullio Gulf (Fig. 2B). The area has an average depth of $10 \mathrm{~m}$ and is characterised by soft bottom sediments with the presence of interstitial infauna.

As for Prelo, sampling was carried out on a monthly basis from January 1991 to January 1992. The sampling station was located $50 \mathrm{~m}$ offshore and was close to the Entella river estuary. The area is exposed to southerly winds and to the main Ligurian current re-suspending the sediments within the $10 \mathrm{~m}$ bathymetric contour [32].

\subsection{Paraggi Bay (Ligurian Sea)}

Paraggi station is located near the headland of Portofino (protected area) and is in a natural inlet surrounded by dense Mediterranean vegetation (Fig. 2C). Sampling was carried out in January and July 2001 at a depth of $1.5 \mathrm{~m}$ [33]. Organic matter content of the sediment is comparable to oligotrophic areas of the Mediterranean Sea [32].

\subsection{La Spezia Bay (Grazie Basin—Ligurian Sea)}

La Spezia station is located beneath a fish farm in a semi-enclosed bay in the Gulf of La Spezia (Ligurian Sea, NW Mediterranean Sea) (Fig. 2D). The farm has been used for approx- 

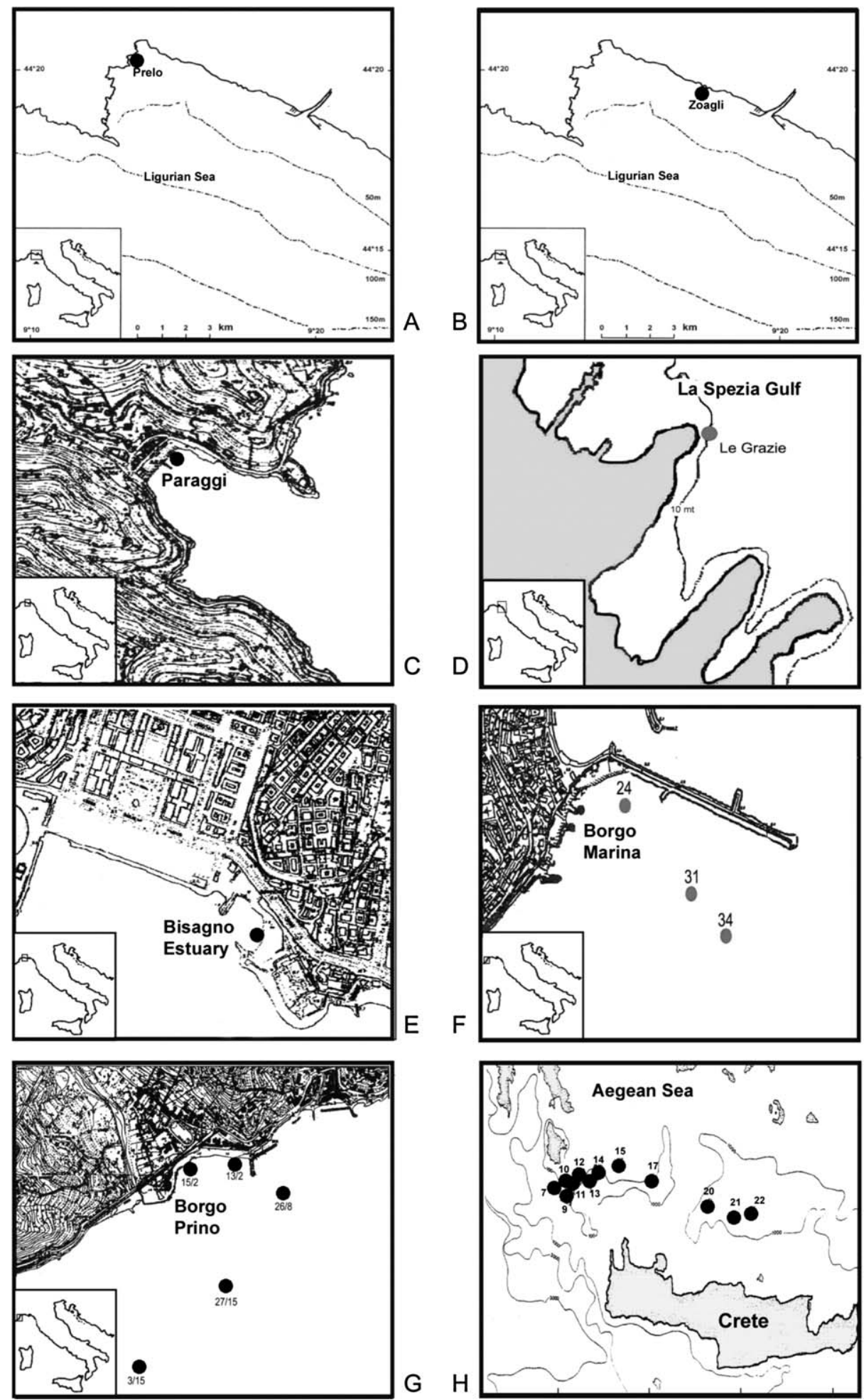

Fig. 2. Sampling stations. 
imately 15 years for the commercial rearing of the gilthead sea bream (Sparus aurata), and, at the time of study, contained a biomass of 16 ton of fish. The study area (water depth $10 \mathrm{~m}$ ) is sheltered and characterised by a low circulation regime. Sediment is mostly composed of mud. Dominant current flow in the NE-NW direction, following the cyclonic circulation of the NW Mediterranean Sea. Sampling was carried out in June and February 2001. Sediments are characterised by extremely elevated concentrations of organic matter compared with concentrations found in highly eutrophicated coastal areas [21,34].

\subsection{Bisagno Estuary (Ligurian Sea)}

Bisagno Estuary station is located near the water treatment plant of Genoa not far from the city harbour (Fig. 2E). Samples were taken a depth of $1.5 \mathrm{~m}$ in January and July 2001 [33]. Organic matter $(\mathrm{OM})$ content of the sediment is comparable to typical OM concentrations in estuaries [35].

\subsection{Borgo Marina (Imperia Coast_Ligurian Sea)}

Borgo Marina station is located east of Borgo Prino along the Imperia Coast (Fig. 2F). Sampling was carried out in June 2000 within $15 \mathrm{~m}$ of depth [33].

\subsection{Borgo Prino (Imperia coast-Ligurian Sea)}

Borgo Prino station is located along the Imperia Coast in the Ligurian Sea. The site is characterised by sand and rocky shores and by the presence of the Prino River outlet (Fig. 2G). As for Borgo Marina, sampling was carried out in June 2000 within $15 \mathrm{~m}$ of depth [33].

\subsection{Cretan Sea (Aegean Sea)}

In the Aegean Sea 12 stations were sampled along a East-West transect near $36^{\circ} \mathrm{N}$ in September 1989. The sampling depth ranged from 110 to $1840 \mathrm{~m}$. This site is one of the more oligothrophic areas of the Mediterranean Sea [36] (Fig. 2H).

\section{Results and discussion}

The evaluation of the sensitivity of $\mathrm{Ex}, \mathrm{Ex}_{\mathrm{sp}}$ and $\mathrm{AS}$ as a function of the considered environmental constraints (Table 3 ) let us to verify that:

- Exergy is strongly influenced by OM concentration and often results are not meaningful for the study of the microbenthic loop sub-system.

- Specific exergy shows a great sensitivity with respect to the structural variations in the microbenthic sub-system such as biomass composition, complexity and recruitment events.

- Variations in ascendency are strongly related to the functionality of the microbenthic loop in particular with the decomposition activity and with the capacity for resource exploitation. 
Table 3

Efficacy of the holistic indicators as a function of the considered environmental variables

\begin{tabular}{llllll}
\hline \multicolumn{7}{c}{} & \multicolumn{2}{l}{ Environmental constrains } \\
\cline { 3 - 6 } & & $\begin{array}{l}\text { Temporal } \\
\text { variability }\end{array}$ & $\begin{array}{l}\text { OM } \\
\text { variability }\end{array}$ & $\begin{array}{l}\text { Depth } \\
\text { variability }\end{array}$ & $\begin{array}{l}\text { Variations in hydro- } \\
\text { dynamic features }\end{array}$ \\
\hline Holistic & Exergy & - & - & - & + \\
indicators & Specific Exergy & + & + & + & + \\
& Ascendency & + & + & $\mathrm{O}$ & - \\
\hline
\end{tabular}

$(+)$ Good variability and significant responses; (-) responses not relevant; $(\mathrm{O})$ responses that need succesive confirmations.

Furthermore, it is of particular interest that comparative analysis of the three indicators reveals the trophic adaptation of the system at different levels of environmental disturbance.

\subsection{Temporal variability}

To assess the temporal variability of exergy and ascendency within the microbenthic loop in marine sediments, we considered the stations of Prelo and Zoagli where the sampling was carried out on a monthly basis for a whole year; differences between the two sites are due to the presence of a large seagrass bed of $P$. oceanica in Prelo Bay. In this site the seasonal variation of total $\mathrm{OM}$ are strongly influenced by $P$. oceanica and in particular by the leaf fall occurring in late summer [32]. Detritus of Posidonia is mostly refractory [35,37] and represents the major component of $\mathrm{OM}$ in the studied environment.

In Prelo, where Posidonia was present, the OM showed a seasonal variation characterised by a stepwise increase from June to March up to a maximum value of 14043 ton $\mathrm{km}^{-2}$ followed by a decrease up to the minimum value of 5890 ton $\mathrm{km}^{-2}$ in July. In contrast, in Zoagli, OM showed a less marked trend and an increase was only observed from November (3547 ton $\mathrm{km}^{-2}$ ) to February (8751 ton $\mathrm{km}^{-2}$ ).

The exergy in Prelo displayed an increasing trend from summer to winter and ranged from a minimum value of $834405 \mathrm{~kJ} \mathrm{~m}^{-2}$ in June to maximum of $1926738 \mathrm{~kJ} \mathrm{~m}^{-2}$ in January (Fig. 3). In Zoagli the exergy variation displayed a less marked increase ranging from a minimum value of $530128 \mathrm{~kJ} \mathrm{~m}^{-2}$ in June to a maximum of $1141346 \mathrm{~kJ} \mathrm{~m}^{-2}$ in February (Fig. 4). The seasonal trend in exergy values resulted in strong correlation with $\mathrm{OM}$ variations both in Prelo and Zoagli $(n=13, p<0.05$ in Prelo; $n=13, p<0.05$ in Zoagli) and this might be explained by the high $\mathrm{OM}$ concentrations having a great influence on the calculation of exergy within the microbenthic loop at the two sites.

In contrast, specific exergy displayed a different trend. In Prelo $\mathrm{Ex}_{\mathrm{sp}}$ showed a stepwise increase from 1.056 in April to 1.404 in October with peak values observed in October-November (Fig. 3). In Zoagli an increase in $\mathrm{Ex}_{\text {sp }}$ was also observed from 1.075 in February to 1.312 in November and two maxima were observed in April (1.520) and November (1.312) (Fig. 4). In the area of Prelo, Danovaro [32] reported an increase of meiofaunal biomass and diversity during leaf fall related to the high input of OM. Meiofauna was also the main biotic component displaying 


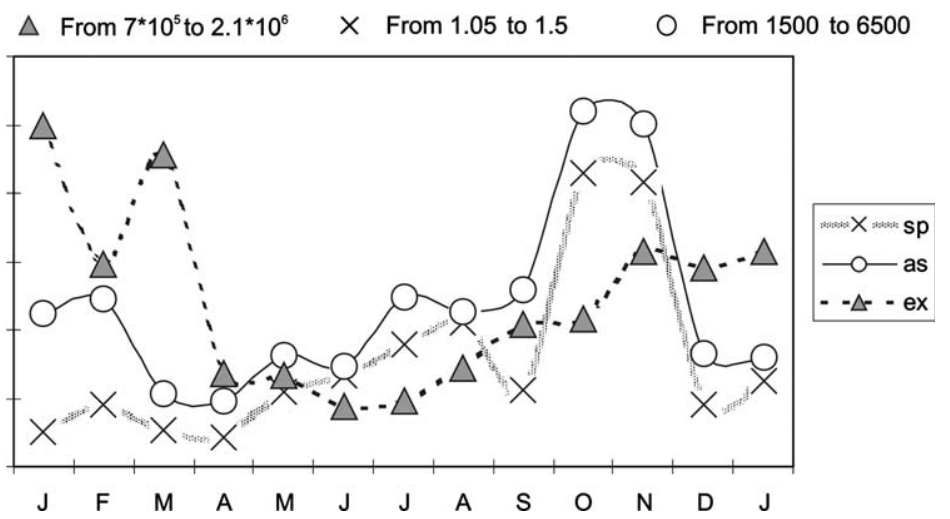

Fig. 3. Seasonal trend of Ex, Ex $x_{s p}$ and $A S$ in Prelo station.

seasonal variation in Prelo sediments. According to Marques et al. [38] the observed increase in specific exergy may thus be due to the increase of specific diversity within the detritus food chain. The decrease of $\mathrm{Ex}_{\mathrm{sp}}$ observed from March to April is then related to unfavourable winter conditions and consequently to a decrease in meiofauna diversity [32].

In Zoagli the observed increase in $\mathrm{Ex}_{\mathrm{sp}}$ can also be associated with an increase in biomass and richness within the microbenthic sub-system [39]. In addition, the maximum in $\mathrm{Ex}_{\mathrm{sp}}$ values in June, at this site, is probably explained by a Polychaete recruitment event observed in the sediment [39]. Ascendency (AS) displayed a similar trend both in Prelo and in Zoagli (Figs. 3 and 4). In both systems minimum values were observed in early spring (1953.6 ton $\mathrm{km}^{-2} \mathrm{year}^{-1}$ in April and 1551.2 ton $\mathrm{km}^{-2}$ year ${ }^{-1}$ in January in Prelo and Zoagli, respectively) and maximum values were observed in autumn (6210.7 and 4668.4 ton $\mathrm{km}^{-2}$ year ${ }^{-1}$ both in October in Prelo and Zoagli, respectively).

Since ascendency is a measure of the overall dynamic and organization of the system, it mostly reflects the decomposition activity that is the primary ecological role played by the microbenthic sub-system. For this reason the maximum in As values was observed in autumn

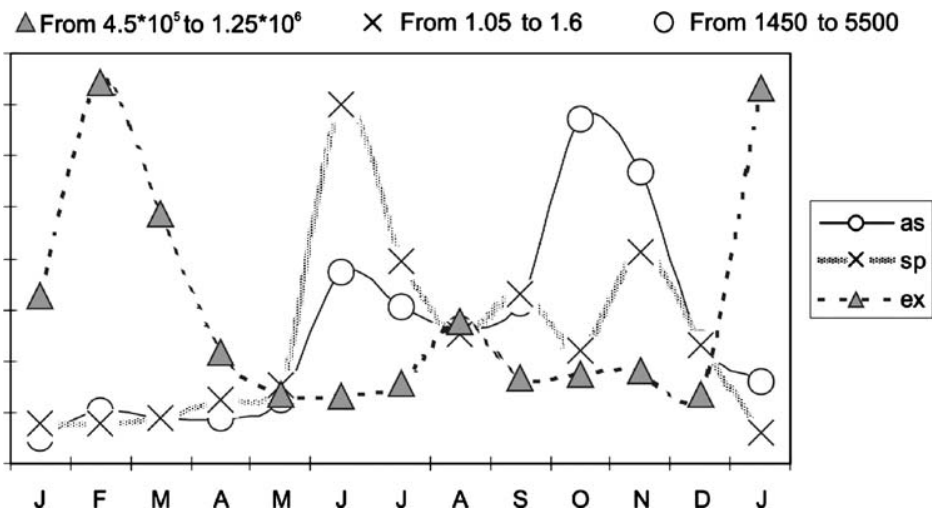

Fig. 4. Seasonal trend of Ex, Ex $\mathrm{sp}_{\mathrm{sp}}$ and in Zoagli station. 
where decomposition is the principal process within the seasonal ecological dynamic of the marine benthic ecosystems [32].

In conclusion, the exergy index calculated within the detritus community highlighted a difference between Prelo and Zoagli mostly based on the presence/absence of P. oceanica. This was mostly due to the difference in OM content characterising the two systems having a major influence on the calculation of exergy. Therefore, exergy values are mainly determined by the variations of biomass (considered as a quantitive measure) more than structural complexity (considered as a qualitative measure) in our system. For this reason, exergy can be considered as a pure quantitative structural measure if calculated for the microbenthic sub-system.

In contrast, specific exergy seemed to provide complementary information, being more powerful in measuring the qualitative components of the system (i.e. structural complexity) more than a quantitative measure (i.e. biomass).

The ascendency index reflected the overall system activity (i.e. decomposition) and can be mostly considered as a measure of the functionality expressed by the microbenthic sub-system in the marine environment.

From these considerations it can be concluded that we observed a shift in the information provided by the three indices giving a pure structural, qualitative and mostly functional evaluation of the ecosystem by the calculation of exergy, specific exergy and ascendency calculated within the microbenthic loop in the marine environment.

\subsection{Spatial variability}

\subsubsection{Variation of Ex and $A S$ with respect to the organic matter concentration in the sediment}

Spatial variability of exergy and ascendency has been investigated in benthic ecosystems having different concentrations of OM in the sediment. To do this, we analysed benthic parameters for the eight ecosystems studied (La Spezia, Bisagno Estuary, Paraggi, Prelo, Zoagli, Borgo Prino, Borgo Marina and the Cretan Sea) from which the samples have been collected during different times of the year.

According to Dell'Anno et al. [20], the OM content is a measure of the trophic state of the benthic ecosystem. The highest OM concentrations were found in La Spezia (17724 and 19694 ton $\mathrm{km}^{-2}$ in winter and summer, respectively) due to the presence of the fish farm. The Bisagno Estuary also displayed high OM concentrations in the sediments $\left(16000\right.$ and 7702 ton $\mathrm{km}^{-2}$ in winter and summer, respectively) especially in winter due to the river outflow. OM concentrations ranging from 5890 (winter) to 14913 ton $\mathrm{km}^{-2}$ (summer) were observed in Prelo as a consequence of the presence of $P$. oceanica. Zoagli displayed a lower concentration of OM ranging from 8751 (winter) to 2789 ton $\mathrm{km}^{-2}$ (summer). The minimum OM concentration was found in Paraggi (3865 and 4063 ton $\mathrm{km}^{-2}$ in winter and summer, respectively).

The Ex values increased with increasing OM concentrations $(n=52, p>0.05)$ and confirmed the dependence of Ex on detritus when calculated for the microbenthic loop system. In contrast, specific exergy showed an opposite trend and displayed a rapid decrease with increasing OM, reaching values close to 1 for OM concentrations greater than 10000 ton $\mathrm{km}^{-2}$ (Fig. 5). Specific exergy of 1 is only obtained in systems characterised by the absence of living biomass where only organic detritus is present. Therefore, the value of specific exergy close to 1 observed in our study indicated a low structural complexity of the benthic system due to a progressive depletion 


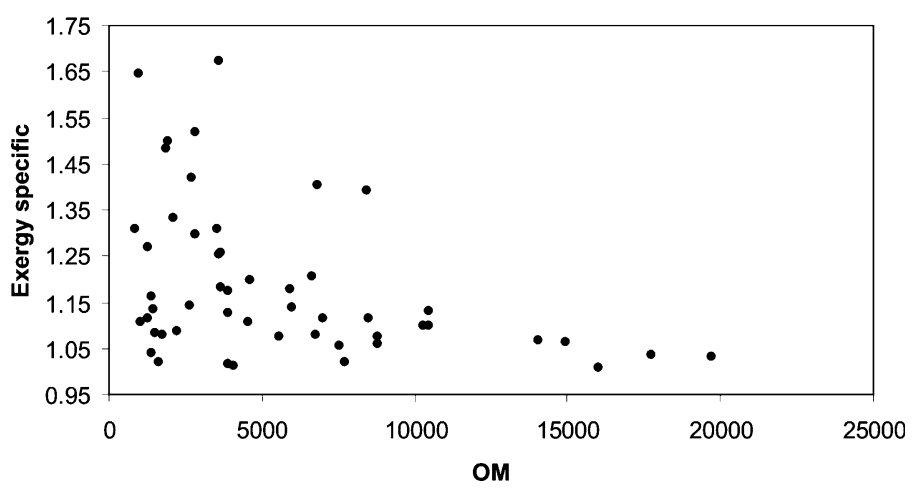

Fig. 5. $\mathrm{Ex}_{\mathrm{sp}}$ variations in function of $\mathrm{OM}$ ammount (ton $\mathrm{km}^{-2}$ ).

of the living biomass at increasing OM concentrations. Ultimately, the $\operatorname{Ex}_{\mathrm{sp}}$ trend reflects a dystrophic stress occurring within the sedimentary system in agreement with what has been observed in other ecosystems such as lake [9] and estuaries [38].

The AS displayed an inverse trend (Fig. 6). Below 10000 ton $\mathrm{km}^{-2}$ of $\mathrm{OM}$ we did not observe any increase in AS values, while over this level we observed a rapid increase in AS. This behaviour is strictly due to variations in throughput and not in information hence it is related to the increase in the system activity and to an increase in the number and magnitude of fluxes directed to and from the detritus group.

The study of $\mathrm{Ex}_{\mathrm{sp}}$ and AS within the microbenthic loop highlighted as benthic ecosystems display different structural and functional adaptations to increasing OM. Over a certain level of organic matter we observed an uncoupling occurring between the structural and functional processes of the system characterised by a decrease in structural complexity $\left(\mathrm{Ex}_{\mathrm{sp}}\right)$ followed by a sudden increase in the functional component and activity (AS).

Uncoupling phenomena between bacterial hydrolysis and the cellular scission in relation to stress due to excessive increase of OM have been found in other areas [40]. Ecosystem behaviour over an OM threshold level is thus comparable to a situation of 'ecosystem fever' where dissipation of energy is required to balance the excessive input of organic material.

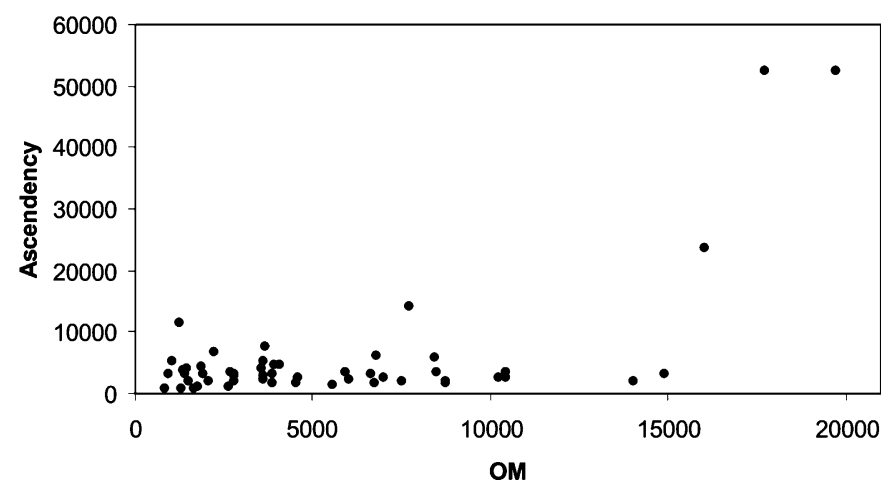

Fig. 6. Ascendency variations (ton $\mathrm{km}^{-2}$ year ${ }^{-1}$ ) in function of $\mathrm{OM}$ ammount (ton $\mathrm{km}^{-2}$ ). 


\subsubsection{Variation of Ex and $A S$ with depth}

To assess the variability of exergy and ascendency with depth in coastal systems, we considered the Imperia case (eight simulations with samples collected within the first $15 \mathrm{~m}$ of depth) and for oceanic systems the Aegean Sea (12 simulations with samples collected at depth between 100 and $2000 \mathrm{~m}$ ).

Ex displayed an increase with depth in both coastal and oceanic systems and this was related to the increase of $\mathrm{OM}$ in the sediment. However, in coastal systems the rate of increase in Ex values $(\Delta \mathrm{Ex} / \Delta$ depth) was different between Borgo Marina (higher) and Borgo Prino (lower). Borgo Marina has a low circulation regime due to the near presence of a harbour seawall. The increase in the $\Delta \mathrm{Ex} / \Delta$ depth may thus be related to the higher deposition rate of $\mathrm{OM}$ in this area. The same variation with depth was also observed for $\mathrm{Ex}_{\mathrm{sp}}$ and the difference in $\Delta \mathrm{Ex}_{\mathrm{sp}} / \Delta \mathrm{de}$ pth between Borgo Prino and Borgo Marina also suggests an increase in structural complexity in the latter (Fig. 7). In contrast, the ascendency values did not show a clear trend either in Borgo Marina and Borgo Prino.

In the Aegean Sea, the $\mathrm{Ex}_{\mathrm{sp}}$ decrease at increasing depth indicated a decrease in the number and the diversity of organisms (e.g. meiofauna) according to Danovaro et al. [36]. In the Oceanic area the decrease in the living biomass [36] did not reflect any change in AS values. These results indicate that the loss in structural complexity observed with depth is not coupled with a decrease in the overall system activity and can be viewed as an increase in ecological efficiency of the deep benthic ecosystem. A possible explanation of this occurrence may be found in the increase in the number of real to possible fluxes expressed within the detritus food chain at increasing depth.

In conclusion both $\mathrm{Ex}_{\mathrm{sp}}$ and $\mathrm{AS}$ were sensitive indicators of variation occurring with changing depth within the microbenthic loop of marine ecosystems. In particular, the change in $\Delta \mathrm{Ex} /$ $\Delta$ depth and $\Delta \mathrm{Ex}_{\mathrm{sp}} / \Delta$ depth in the coastal area reflected a variation in $\mathrm{OM}$ deposition rates and in biomass composition and complexity due to the differences in physical structure such as hydrodynamic features and/or bottom morphology of the coastal ecosystem. Ascendency described an increase in ecological efficiency within the microbenthic loop at increasing depth and this was particularly evident over great depth in the benthic oceanic ecosystem.

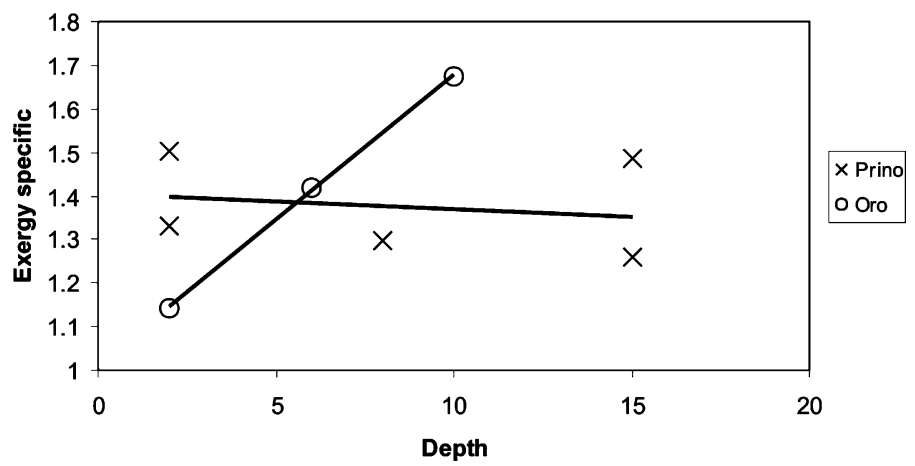

Fig. 7. $\mathrm{Ex}_{\mathrm{sp}}$ variations in function of depth in Borgo Prino and Borgo Marina stations. 


\section{Conclusions}

The analysis of the temporal and spatial changes of Ex, Ex $x_{\mathrm{sp}}$ and $\mathrm{AS}$ showed the different behaviours of ecological indicators within the microbenthic loop system. Exergy was strongly correlated with the OM concentrations in the sediments, specific exergy result related to the microbenthic loop structure and complexity while ascendency mostly reflected its activity and organization. In addition, the exergy variations displayed greater seasonal variability while specific exergy and ascendency displayed similar seasonal trend when calculated for different environments. This may result from a convergence in the microbenthic loop functionality within natural benthic ecosystems. The study of the system functionality (AS) other than its structure (Ex) may thus provide a useful information for the assessment of health in different environments.

This can be further highlighted in terms of changes in exergy and ascendency with increasing OM. In particular, over a certain level of OM, we observed an uncoupling occurring between the two indices comparable to a situation of 'ecosystem fever' where dissipation of energy is required to balance the excessive input of organic material.

Both Ex and AS were sensitive indicators of variations occurring with changing depth in the marine ecosystem. An uncoupling between Ex and AS was also observed with increasing depth in the oceanic system and this was the result of natural adaptations of the benthic system to an extreme environmental condition.

In conclusion the temporal and spatial changes of exergy and ascendency within the microbenthic loop appeared to be sensitive to the changes in environmental conditions and in the trophic state and may therefore be proposed as useful tool for the health assessment of marine benthic ecosystem.

\section{References}

[1] Campbell DE. Using energy systems theory to define, measure, and interpret ecological integrity and ecosystem health. Ecosystem health 2000;6(3):181-204.

[2] Christensen V. Ecosystem maturity—-toward quantification. Ecological Modelling 1995;77:3-32.

[3] Costanza R. Toward an operational definition of ecosystem health. In: Costanza R, Norton BG, Haskell BD, editors. Ecosystem health, new goals for environmental management. Washington, DC and Covelo, CA: Island Press, 1992.

[4] Mageau MT, Costanza R, Ulanovicz RE. Quantifying the trends expected in developing ecosystems. Ecological Modelling 1998;112:1-22.

[5] Jørgensen SE. Review and comparison of goal functions in systems ecology. Vie le Milieu 1994;44(1):11-20.

[6] Jørgensen SE. The application of ecological indicators to assess the ecological condition of a lake. Lakes Reservoirs: Research Management 1995;1:177-82.

[7] Jørgensen SE. Application of exergy and specific exergy as ecological indicators of coastal areas. Aquatic Ecosystem Health and Management 2000;3:419-30.

[8] Xu F-L, Jørgensen SE, Tao S. Ecological indicators for assessing freshwater ecosystem health. Ecological Modelling 1999;116:77-106.

[9] Xu F-L, Dawson RW, Shu T, Ben-Gang L, Jun C. System-level responses of lake ecosystems to chemical stresses using exergy and structural exergy as ecological indicators. Chemosphere 2002;46:173-85.

[10] Nielsen SN, Costanza R, Ulanowicz RE. Quantifying the trend expected in developing ecosystems. Ecological Modelling 2000;112:1-22. 
[11] Ulanowicz RE. Growth and development: ecosystems phenomenology. New York: Springer-Verlag; 1986.

[12] Meyer HF, Jørgensen SE. Energy and ecological buffer capacity. In: Jørgensen SE, editor. State of the art of ecological modelling. Environmental sciences and applications. Proceedings of the 7th Conference on Ecological Modelling, 28 August-2 September 1978, Copenaghen. Copenaghen: International Society for Ecological Modelling; 1979 , p. 829-46.

[13] Christensen V. On the behaviour of some proposed goal function for ecosystem developement. Ecological Modelling 1994;75/76:37-49.

[14] Pérez-España H, Arreguín-Sánchez F. A measure of ecosystem maturity. Ecological Modelling 1999;119:79-85.

[15] Pérez-España H, Arreguín-Sánchez F. Complexity related to behavior of stability in modeled coastal zone ecosystems. Aquatic Ecosystem Health and Management 1999;2:129-35.

[16] Pérez-España H, Arreguín-Sánchez F. An inverse relationship between stability and maturity in models of aquatic ecosystems. Ecological Modelling 2001;145:189-96.

[17] Azam F, Fechel T, Field JG, Gray JS, Meyer-Reil LA, Thingstad F. The ecological role of water-column microbes in the sea. Marine Ecology Progress Series 1983;10:257-63.

[18] Boyd SE, Rees HL, Richardson CA. Nematodes as sensitive indicators of change at dredged material disposal sites. Estuarine, Coastal and Shelf Science 2000;51:805-19.

[19] Lee MR, Correa JA, Castilla JC. An assessment of the potential use of the nematode to copepod ratio in the monitoring of metals pollution. The Chañaral Case. Marine Pollution Bulletin 2001;42:696-701.

[20] Dell'Anno A, Mei ML, Pusceddu A, Danovaro R. Assessing the trophic state and eutrophication of coastal marine systems: a new approach based on the biochemical composition of sediment organic matter. Marine Pollution Bullettin 2002;44(7):3611-22.

[21] Vezzulli L, Chelossi E, Riccardi G, Fabiano M. Bacterial community structure and activity in fish farm sediment of the Ligurian Sea (Western Mediterranean). Aquaculture International 2002;10(2):123-41.

[22] Marques JC, Jørgensen SE. Three selected ecological observations interpreted in terms of a thermodynamic hypothesis. Contribution to a general theoretical framework. Ecological Modelling 2002;158(3):213-21.

[23] Ulanowicz RE, Abarca-Arenas LG. An informational synthesis of ecosystem structure and function. Ecological Modelling 1997;95:1-10.

[24] Christensen V, Walters CJ, Pauly D. Ecopath with Ecosim Version 4, Help system $\mathbb{C}$. University of British Columbia, Fisheries Centre, Vancouver, Canada and ICLARM, Penang, Malaysia; 2000. Available from: http://www.ecopath.org.

[25] Plante-Cuny MR, Evaluation par spectrophotomètrie des teneurs en chlorophyll-a functonelle et en phaeopigments des substrats meubles marins. ORSTOM Nosy-Bé; 1974.

[26] Meyer-Reil LA. Benthic responses to sedimentation events during autumn to spring at a shallow water station in the Western Kiel Bight. II Analysis of benthic bacterial populations. Marine Biology 1983;77:247-56.

[27] Wieser W. Die beziehung zwischen mundhohlengestalt, ernahrungsweise und vorkommen bei freilebenden marinen Nematoden. Eine okologisch-morphologische studie. Arkiv for Zoologi 1953;4:439-84.

[28] Warwick RM, Price R. Ecological and metabolic studies on free-living nematodes from an estuarine mud-flat. Estuarine Coastal Marine Science 1979;9:257-71.

[29] Romeyn K, Bowman LA. Food selection and consumption by estuarine nematodes. Hydrobiology Bullettin 1983;17(2):103-9.

[30] Wieser W. Benthic studies in Buzzard Bay. II the meiofauna. Limnology and Oceanography 1960;5:121-37.

[31] Parker JG. A comparison of methods used for the measurement of organic matter in marine sediment. Chemistry and Ecology 1983;1:201-10.

[32] Danovaro R. Detritus-Bacteria- Meiofauna interactions in a seagrass bed (Posidonia oceanica) of the NW Mediterranean. Marine Biology 1996;127:1-13.

[33] Marrale, D., Flusso di materia ed energia in sistemi sedimentari caratterizzati da differenti condizioni trofiche. Environmental Science PhD thesis, University of Genova; 2001.

[34] Vezzulli L, Marrale D, Moreno M, Fabiano M. Sediment organic matter and meiofauna community response to long-term fish-farm impact in the Ligurian Sea (Western Mediterranean). Chemistry and Ecology 2003;19:431-40.

[35] Fabiano M, Danovaro R. Composition of organic matter in sediment facing a river estuary (Tyrrenian Sea): relationship with bacteria and microphytobenthic biomass. Hydrobiologia 1994;277:71-84. 
[36] Danovaro R, Della Croce N, Eleftheriou A, Fabiano M, Papadopoulou N, Smith C, Tselepides A. Meiofauna of the deep Eastern Mediterranean Sea: distribution and abundance in relation to bacterial biomass, organic matter composition and other environmental factors. Progress in Oceanography 1995;36:329-41.

[37] Velimirov B. DOC dynamics in a Mediterranean seagrass system. Marine Ecological Progress Series 1986;28:21-41.

[38] Marques JC, Pardal MÂ, Nielsen SN, Jørgensen SE. Analysis of the properties of exergy and biodiversity along estuarine gradient of eutrophication. Ecological Modelling 1997;102:155-67.

[39] Danovaro R, Analisi della dinamica e della struttura trofica di comunità meiobenthoniche in relazione al contenuto ed alla composizione della sostanza organica particellata (Mar Ligure). Environmental Science PhD thesis, University of Pisa; 1993.

[40] Fabiano M, Misic C, Manini E, Danovaro R, Povero P, Chiatti S. Distribution and biochemical composition of suspended and sedimentary organic matter in the northern Adriatic. In: Faranda FM, Guglielmo L, Spezie G, editors. Structure and processes in the Mediterranean ecosystems, 57. Springer-Verlag; 2001, p. 447-54. 